\title{
Linguagem e mundo: Wittgenstein e Manoel de Barros
}

\author{
Osmar Pereira Oliva*
}

\section{Resumo}

Este ensaio pretende discutir concepções de linguagem e de mundo, a partir da filosofia wittgensteiniana presente no Tractatus Logico-philosophicus, e da poética de Manoel de Barros, em Livro sobre nada. Discutirá, também, os conceitos de forma lógica, verdade e figuração, com exemplos de estruturas lingüísticas poéticas, aproximando proposição filosófica e criação literária.

\section{Palavras-chave}

Filosofia. Poesia. Linguagem. Mundo.

\begin{abstract}
Ludwig Joseph Johann Wittgenstein nasceu em Viena (Áustria), a 26 de Abril de 1889, e faleceu em Cambridge, a 29 de Abril de 1951. É considerado um dos maiores filósofos do século XX, tendo contribuído com diversas inovações nos campos da lógica, da filosofia da linguagem e da epistemologia. O Tractatus LogicoPhilosophicus, seu primeiro livro, foi o único publicado em vida (1921). Dele, abstrairemos algumas reflexões acerca da linguagem e do mundo.

Manoel Wenceslau Leite de Barros nasceu em Cuiabá (Brasil), a 19 de dezembro de 1916. Seu primeiro livro, Poemas concebidos sem pecado, foi publicado em 1937. Desde a década de 1930, publicou mais de 20 livros, tendo como temática o pantanal, representado através de sua natureza e do cotidiano. No entanto, utilizaremos neste ensaio apenas o Livro sobre nada, porque acreditamos encontrar nele elementos suficientes para refletir sobre linguagem e mundo numa perspectiva comparativa com a filosofia do Tractatus.
\end{abstract}

A princípio, cumpre esclarecer o que possibilita colocar em comparação a filosofia e a poesia e, mais especificamente, como articular o pensamento de um homem que estudou Matemática, Física e Engenharia mecânica ao pensamento de outro homem, dedicado à poesia.

Wittgenstein, no Tractatus, alude aos mentalismos, no sentido de que, para cada coisa, haveria um nome guardado na memória, que ativamos quando precisamos determinar algo, como se fosse uma tabela mental. No entanto, a linguagem não é

\footnotetext{
* Pós-doutor. Universidade Estadual de Montes Claros - Unimontes.
} 
pré-determinada nem está pronta e fixada na memória, de forma que a utilização dos nomes pode desencadear jogos inusitados e múltiplos, como acontece na elaboração poética. Nas Investigações Filosóficas, o filósofo também critica a linguagem privada, uma vez que ela deve abarcar a multiplicidade de sentidos e ser compreendida pelas comunidades. Essa verdade, solipsista, é correta, porque cada sujeito projeta nomes sobre os objetos e sobre as coisas, criando seus próprios mundos, mas é também uma verdade imperfeita, porque todas as pessoas são capazes de construirem seus mundos, o que equivale a realidades individuais, não compartilhadas, portanto. Como afirma Eduardo Simões (2008, p. 60): "O mundo não é, pois, uma coisa nem um amontoado de coisas, haja vista que do mesmo amontoado de coisas podem ser construídos os mais diversos mundos. E o nosso mundo real é apenas um ponto no espaço lógico onde são pensáveis outros pontos, isto é, outros mundos possíveis."

O que Wittgenstein discute em seu Tractatus é exatamente essa concatenação de objetos, constituindo os fatos, a que denominou de mundo. Para a representação de mundo, o filósofo procurou dar à linguagem um caráter científico, "isentando-a de todo e qualquer equívoco que pudesse ser produzido pela sua forma superficial." (SIMÖES, 2008, p. 52) Enquanto o objeto é uma condição de possibilidade do mundo - posto que seja um constituinte da realidade, o nome é uma condição de possibilidade da linguagem. E um dos principais equívocos da linguagem consiste na descrição. O nome não é passível de análise, porque perde a sua referencialidade; o objeto é indestrutível, imutável e indescritível, porque cada combinação de objetos acarreta um fato diverso.

A linguagem ideal, segundo Wittgenstein nessa obra em foco, deveria fazer desaparecer as descrições para que se chegassem aos nomes e, assim, a um sentido plenamente determinado. As descrições, enquanto enunciados complexos, produzem ambigüidades, pois dizem muitas coisas a respeito do mundo e a nomeação, ao contrário, determina e especifica o objeto. Aqui, cumpre-nos adiantar a primordial diferença da filosofia lógico-formal em relação ao discurso poético, que mais à frente abordaremos. Na poesia, quanto mais simples for o enunciado, mais complexo ele se torna; os nomes, sozinhos e isolados, ganham mais ambigüidade e multiplicidade de sentidos do que quando estão combinados, concatenados em arranjos descritivos.

Mas então, que aproximação poderia se estabelecer entre esse Wittgenstein e um poeta como Manoel de Barros? Na sua concepção de mundo, o filósofo aponta que o objeto, por si só, nada determina do mundo, mas é a concatenação dos objetos em suas relações uns com os outros que configuram os fatos, e, na concordância ou discordância de seus sentidos com a realidade, pode-se determinar a falsidade ou a veracidade das proposições. Para esse exercício comparativo, há um elemento comum entre a linguagem e o mundo, a forma lógica, pela qual compreendemos como se dá a correspondência entre esses dois domínios. Note-se que Wittgenstein, em nenhum momento do Tractatus se preocupou em definir o objeto e provar a sua existência, antes, promove uma reflexão sobre as condições de possibilidade de sua existência e as suas relações na constituição de fatos. Isto é semelhante na poesia. No ato da figuração, o sentido se processa no "eu", sujeito transcendental, que projeta nomes 
sobre os objetos, dotando os sinais de sentidos e promovendo a "coordenação de fatos por meio da coordenação de seus objetos." (In SIMÕES, 2008, p. 61)

O sujeito transcendental é um conceito, cuja finalidade consiste em afastar-se dos sentimentos, para $o$ uso da razão e, assim, ganhar universalidade e imparcialidade. A função desse sujeito transcendental é de escolha: ele deve determinar a qual objeto tal nome deve ser coordenado. Nessa relação projetiva, o sujeito transcendental estabelece uma conexão entre o objeto e a linguagem. Mas, retomando a aproximação da filosofia wittgesteiniana com a poesia, é a forma lógica o principal ponto de contato nesses discursos aparentemente tão distantes e diversos. Eduardo Simões (2008, p. 64), comentando Glock (1998, p. 178), afirma que "a lógica nos fornece 'normas de representação', regras para a transformação de símbolos, para se passar de premissas a conclusões. Ela possui, assim, a extraordinária importância de ser a armação formal da linguagem, do pensamento e do mundo."

O que há de comum entre o nome e a coisa que ele representa? Ainda que Wittgenstein não nos ofereça uma resposta conceitual sobre essa relação, podemos compreender que, através da estrutura lógica da linguagem podemos compreender a estrutura lógica do mundo. Assim, a poesia se elabora por meio de arranjos de nomes cujas proposições apresentam uma estrutura lógica da linguagem, sem exigir do leitor que hajam de fato o objeto e as coisas que ela representa. A poesia traduz um pensamento, faz asserções acerca do mundo e pode ser compreendida como uma condição de possibilidade de sua existência, não a sua realidade científica. Nas palavras de Simões (2008, p. 66), "O cimento lógico que une as proposições elementares numa proposição complexa são os conectivos lógicos. E a estrutura lógica das proposições é uma imagem das combinações de estados de coisas possíveis na realidade. Todo fato possível deixa-se representar na proposição e cada uma dessas define uma determinada posição no espaço lógico, no qual têm lugar todos os fatos."

É evidente que no, Tractatus, a forma lógica está relacionada à condição de verdade ou de falsidade das proposições, ao estabelecer a isomorfia entre os dois domínios (da linguagem e do mundo). No entanto, o que aproveitamos dessa filosofia não é o seu aspecto científico e, sim, a sua teorização das equivalências, das correspondências, ou, em outras palavras, a linguagem como um meio comum que possibilite a verdade ou a falsidade de uma proposição, ainda que o discurso poético não tenha qualquer pretensão científica. Assim, tanto na filosofia wittgensteiniana quanto na poesia, há uma forma lógica que possibilita, pela identidade formal entre a linguagem e o mundo, que haja uma representação, uma correspondência, ou uma figuração. Essa isomorfia pode ser pensada a partir do elo que existe entre o nome e a coisa, ou seja, o arquétipo do mundo é igual ao arquétipo da linguagem. Assim como os nomes se concatenam para uma proposição que dê sentido ao mundo, os objetos estão dispostos em um espaço lógico formal.

A figuração é um modo de realidade que pode representar a existência ou inexistência de estados de coisas, assim como vemos nos textos poéticos. Ela não descreve o mundo, através de um acesso direto, mas sim através de delimitações no espaço lógico, a partir da possibilidade de seus elementos estarem em estados de coisas. Para Wittgenstein (1995, p. 135.): "O estado de coisas é uma ligação de objetos (coisas). É essencial para a coisa poder ser parte constituinte de um estado de 
coisas. Na lógica, nada é casual: se a coisa pode aparecer no estado de coisas, a possibilidade do estado de coisas já deve estar prejulgado na coisa."

De acordo com o Tractatus, tudo que pode ser pensado também pode ser dito. Os limites da linguagem são, portanto, os limites do pensamento. E é com essa afirmação que passamos, agora, a refletir sobre concepções de mundo e de linguagem na poesia de Manoel de Barros.

No prefácio do seu livro, a que chamou de "pretexto", Manoel de Barros adverte e esclarece ao seu leitor de que "O que eu gostaria de fazer é um livro sobre nada. [...] Mas o nada de meu livro é nada mesmo. É coisa nenhuma por escrito: um alarme para o silêncio, um abridor de amanhecer, pessoa apropriada para pedras, o parafuso de veludo, etc etc. O que eu queria era fazer brinquedos com as palavras. Fazer coisas desúteis. O Nada mesmo. Tudo que use o abandono por dentro e por fora" (BARROS, 2001, p. 7)

O poeta, consciente de que a linguagem literária não precisa ter relação direta com a realidade nem pretende alcançar a cientificidade, observa logo que o seu discurso deve ser compreendido como jogo, brincadeira com as palavras. Um livro sobre nada é um livro? Se é um livro, o que é o nada? O nada pode ser escrito? Essas são as primeiras complexidades que encontramos sob a aparente simplicidade do texto poético de Manoel de Barros.

Aqui, não pretendemos responder a essas questões, mas, a partir dos fundamentos wittgensteinianos do Tractatus, podemos afirmar que existe uma forma lógica no Livro sobre nada. Essa forma lógica pode conduzir o leitor à conclusão de que as coisas representadas pelo poeta cuiabano existem ou não existem. Mas o mais importante é a figuração que é construída antes que o leitor chegue a essa conclusão há uma possibilidade de os elementos encontrarem-se em um estado de coisas de tal maneira que praticamente não duvidamos das afirmações feitas nessa poesia, como "Eu pendurei um bentevi no sol..." ou "As distâncias somavam a gente para menos" ou (BARROS, 2001, p. 11) Lingüisticamente, nada é estranho nesses versos, considerando as suas estruturas lógicas, de forma que, no primeiro verso, temos um pronome pessoal do caso reto, na função de sujeito (Eu), um verbo transitivo direto indicativo de ação (pendurei), uma preposição (em + o) e um substantivo concreto (sol), o qual, combinado com a preposição que o antecede, funcionam como adjunto adverbial de lugar. No entanto, para o Tractatus, existe uma diferenciação entre verdade e validade. Em termos "lógicos", tais versos podem ser, dentro de uma estrutura lingüística formal, válidos; mas quanto ao sentido objetivado, falsos. Isso se justifica, como procuramos discutir, devido aos recursos próprios da literariedade, os quais promovem o desvio intencional do significado das palavras, deixando-as em total liberdade e "promiscuidade".

Assim, temos o que Wittgenstein chamou de figuração, pois os nomes eu, pendurei, um, bentevi, no, sol estão concatenados, formando uma proposição que, de certa maneira, dá sentido ao mundo. Conforme demonstramos gramaticalmente, esses elementos todos estão dispostos no espaço lógico formal e, garantir a existência desses objetos não é nosso interesse, como também não foi o objetivo do filósofo no Tractatus. Antes, o que pretendemos é refletir sobre as condições de possibilidade de 
as coisas serem representadas por meio de figurações e proposições, cujos objetos estejam dispostos compreensivelmente no espaço lógico formal.

Inicialmente, já desconstruiremos a afirmação de Manoel de Barros de que o seu livro será um livro sobre nada. Ao afirmar o nada, afirma-se também o seu contrário. Dizer o nada é dizer algo que o nada é; portanto, o nada é sempre alguma coisa. No segundo verso, acima citado, é racionalmente aceitável que as distâncias somem as pessoas para menos se considerarmos que, à medida que nos afastamos fisicamente também diminuímos em imagem visível, até desaparecermos no horizonte. Em outros versos, o poeta escreve: "Bernardo fala com pedra, fala com nada, fala com árvore." (BARROS, 2001, p. 31) O que, aparentemente, é um discurso da desrazão encontra-se plenamente concatenado em uma proposição lógica e, assim como apontamos um sentido real para o verso anterior, neste também podemos encontrar afirmações verdadeiras, no plano do discurso obviamente, porque os sentidos que o poeta deseja atingir são exatamente aqueles que se distanciam do aparente.

Segundo o eu-lírico do Livro sobre nada, "Preciso de atrapalhar as significâncias. O despropósito é mais saudável do que o solene."(BARROS, 2001, p. 43) É aí, nas encruzilhadas do verídico e do inverídico que o poético se instaura e se instala, pelo desvio, pelos atalhos semânticos. Enquanto no Tractatus Wittgenstein discute que as descrições devem ser evitadas na linguagem científica porque elas promovem desvios de sentidos e ambigüidades, no texto poético as descrições devem ser evitadas porque elas tiram das proposições o que há de essencial na poesia: as suas múltiplas referências e sugestões. Para atingir esse efeito, Manoel de Barros utiliza então versos curtos e, quase sempre, sem enjembments (encadeamentos), o que destitui boa parte de sua poesia do aspecto narrativo, cronístico. Em outras palavras, a poesia desse autor caracteriza-se mais por máximas e aforismos, à semelhança dos ditos e provérbios populares, do que por descrições, salvas algumas exceções que ora deixamos de comentar. Alguns exemplos de figurações não descritivas:

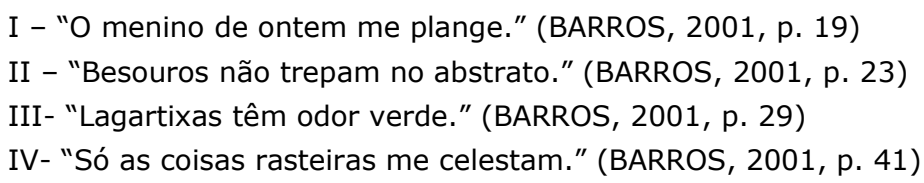

À exceção do primeiro verso, que, sozinho, constitui um poema, os demais são excertos de poemas maiores. Deslocados assim, de seu lugar de origem, são exemplos de uma linguagem que ganha multiplicidade semântica pela concisão e pela síntese, uma vez que não descrevem nem explicam nada. Se retomarmos o segundo exemplo, no contexto em que se encontra inserido no Livro sobre nada, temos: "Meu irmão veio correndo mostrar um brinquedo que/inventara com palavras. Era assim:/Besouros não trepam no abstrato." (BARROS, 2001, p. 23) Como se pode ver, o poema todo é uma brevíssima narração com apenas três versos, mas o que se conta não se pode provar, posto que o brinquedo seja feito de palavras. Segundo, o substantivo da última enunciação (besouros), gramaticalmente da ordem do concreto, associa-se ao "impossível", não trepar no abstrato. Mesmo assim, os objetos estão logicamente 
dispostos no espaço formal da estrutura lingüística da língua portuguesa do Brasil, constituindo uma figuração. A verdade, ou a figuração, no Tractatus, ocorre quando "Um nome toma o lugar de uma coisa, um outro, o de uma outra coisa, e estão ligados entre si, e assim o todo representa - como um quadro vivo - o estado de coisas." (WITTIGENSTEIN, 1995, p. 171) Neste sentido, a verdade é pontual, atômica.

Retomando o poema, se fizéssemos um desmembramento "científico" da linguagem gramatical formal, teríamos algumas "verdades" pontuais, a saber: dois períodos compostos cinco orações, sendo o primeiro com três orações, uma principal e duas subordinadas, e o segundo com uma oração principal e uma coordenada assindética:

1. Meu irmão veio correndo

2. Mostrar um brinquedo

3. Que inventara com palavras

4. Era assim:

5. Besouros não trepam no abstrato

Pontualmente, cada oração tem um sentido, uma verdade que não nos convém aqui explicar ainda mais, para não cansar o leitor e também porque, ao contrário do Tractatus, a "verdade" poética deve ser buscada no contexto e, não, nas estruturas atômicas da linguagem, como demonstramos acima. O eu-lírico construído por Manoel de Barros tem consciência de que o poético reside mesmo é nos desvios da semântica normativa, por meio dos jogos com as palavras, como percebemos no seguinte trecho de poema:

Sei que fazer o inconexo aclara as loucuras.

Sou formado em desencontros.

A sensatez me absurda.

Os delírios verbais me terapeutam.

Posso dar alegria ao esgoto (palavra aceita tudo). (BARROS, 2001, p. 49)

Em relação à verdade pontual, considerando o poema como um todo, poderíamos desmembrar os versos e encontrar sentido, não para cada nome, como o quer Wittigenstein, mas para cada proposição individual, atomizada, como em "Sei que fazer o inconexo aclara as loucuras", o que é comum na poética de Manoel de Barros, conforme afirmamos anteriormente. Muitos desses nomes utilizados pelo poeta não apontam para o objeto no mundo; o que há é uma condição de possibilidade de concatenação dos objetos no espaço lógico, formando estados de coisas.

Portanto, são expressões válidas, com sentido literário, porém falsas (enquanto não existentes no mundo). Esta é, pois, a diferença entre sentido e verdade (figuração), segundo o Tractatus.

Finalizando essa breve reflexão, gostaríamos ainda de fazer uma aproximação entre essas estruturas poéticas pontuais e o sujeito transcendental, presente no Tractatus. Para cada uma dessas "verdades" pontuais, podemos pensar no 
posicionamento do eu-lírico frente a uma situação inusitada que necessita ser dita, nomeada. Para Wittgenstein, o sujeito empírico deve afastar-se de seus sentimentos para utilizar-se da razão em seus atos de nomeação, daí surgindo o sujeito transcendental; na poesia, também há um ato de duplicação. Para o poeta, é ordinário despersonalizar-se e assumir uma outra identidade - persona, a fim de realizar o ato poético e transferir, em forma de linguagem, os seus sentimentos e percepções. Assim:

A ciência pode classificar e nomear os órgãos de um Sabiá

Mas não pode medir seus encantos.

A ciência não pode calcular quantos cavalos de força Existem

Nos encantos de um sabiá.

Quem acumula muita informação perde o condão de Adivinhar: divinare.

Os sabiás divinam. (BARROS, 2001, p. 53)

De Wittgenstein, lembramos que tudo o que pode ser pensado pode ser dito e, se não há nada a dizer, que se cale. Então o Livro sobre nada, de Manoel de Barros, por todas as coisas que diz, mascarado e ensombrado pelo discurso tagarela do não estar dizendo, é um livro sobre tudo, no qual o pensamento em ação elabora simples e belas metáforas, a partir das coisas pequenas e dos sentimentos comumente tidos como superficiais e banais. Uma poesia que se aproxima da filosofia, ao convocar o leitor a pensar sobre aquilo que está, quase sempre, ao rés-do-chão, pouco percebido e valorizado pelos homens, mais voltados para as tecnologias e para as descobertas científicas, em um tempo no qual o poder econômico e a cultura de massa predominam - a imagem visual e a rapidez concorrem, por desigualdade infelizmente, com a linguagem filosófica e com a linguagem poética: sombrios tempos!

\section{Referências:}

BARROS, Manoel de. Livro sobre nada. Rio de Janeiro/São Paulo: Record, 2001.

GLOCK, In SIMÕES, Eduardo. Wittgenstein e o problema da verdade. Belo Horizonte: Argumentum, 2008.

SIMÕES, Eduardo. Wittgenstein e o problema da verdade. Belo Horizonte: Argumentum, 2008.

WITTGENSTEIN, L. Tractatus Logico-Philosophicus. B. Russell, F. R. S. - Introdução. Trad., apres. e ensaio introdutório de Luiz Henrique Lopes dos Santos. S. Paulo: EDUSP, 1995.

WITTIGENSTEIN, L. Investigações filosóficas. Col. Pensadores. São Paulo: Abril, 1996. 


\section{Title}

Language and World: Wittgenstein and Manoel de Barros

\section{Abstract}

The present essay discusses conceptions of language and of world based on the wittgensteinian philosophy as presented in his Tractatus Logico-philosophicus, and on Manoel de Barros's book Liveo sobre nada. A discussion is also made on the concepts of logic, truth and figuration, with examples of poetic linguistic structures in a way to bring closer philosophical proposition and literary creation.

\section{Keywords}

Philosophy. Poetry. Language. World.

Recebido em 20.04.2011. Aprovado em 11.07.2011. 